\title{
A Focused Curriculum Improving the Written English from Russian Speak- ing Engineers
}

\author{
Julia Ziyatdinova, \\ Dr. Phillip Albert Sanger, Purdue University, West Lafayette \\ Dr. Artem Bezrukov, Kazan National Research Technologcal University, Russia
}

Artem Bezrukov graduated from Kazan State Technological University in 2007 and received his $\mathrm{PhD}$ in 2010 at the Department of Physical Chemistry at the same university. His major study area was chemical engineering. He also obtained a degree in professional translation and linguistics. Artem was given the lecturer position at the Department of Physical Chemistry in 2010. He took the position of an associate professor in 2011. His area of responsibilities included practical workshops for the engineering students. He also teached a course of Computer Assisted Translation at the Department of Foreign Languages for Professional Communication. Dr. Bezrukov was invited to join the International Affairs team of Kazan National Research Technological University in March 2011. He headed Protocol Office in 2012 and focused on incoming academic mobility such as international delegations and scholars as well as on the development of collaboration with the university partners in the USA. Dr. Bezrukov has several awards, grants and scholarships including Fulbright RIEA Scholarship in 2012; Scholarship of the Russian Federation Government in 2009; Fellowship of the Republic of Tatarstan Government for Academic Research in 2008. Dr. Bezrukov is the author or co-author of 40 research publications.

Dr. Phillip Albert Sanger, Purdue University, West Lafayette Dr. Phillip Albert Sanger, Purdue University, West Lafayette 


\section{A Focused Curriculum Improving the Written English from Russian Speaking Engineers}

Internationalization of engineering education is the necessary prerequisite for successful development of regional and national economies. A truly all-embracing engineering education should be global today in nature and thus requires a universal platform to overcome boundaries between states. English as the world language is one of such possible platforms and an indispensable component of the 360-degrees engineering education paradigm as it is the connecting link eliminating borders and distances between continents as well as contributing to the collective intellectual potential of mankind. Integration of nonnative engineering students and professionals into this global intellectual network faces untypical challenges, such as significant efforts needed to form an English-speaking engineering community in countries with no or poor historical linguistic English background.

Russia definitely belongs to the group of such countries and is successfully solving the problem of forming primary English teaching and speaking environment.

The difficulty faced in this regard is the difference between the English language, belonging to the family of Germanic languages (the group includes English, German, Dutch, Norwegian, Swedish, Danish) and the Russian language, belonging to the family of Slavic languages (the group includes Russian, Polish, Ukrainian, Belarusian, Macedonian, Czech, Slovak). Both language families have the same roots in the Indo-European language, however, in the course of time, a number of changes came about. The most obvious difference is the alphabet: Latin versus Cyrillic. In English, the letters can be read in different ways depending on the type of syllable, stress, position in the word and the neighboring letters. In many cases, combinations of letters give one sound. And every rule has a number of exceptions. Moreover, the English sounds are very different from the Russian ones. For example, the Russian vowel sounds have neither diphthongs (like in way, no, sky), nor thriphthongs (like in hour, fire).Moreover, the length of the vowel sound makes no difference while, in English, this can change the meaning of the word (like in sheep and ship). A number of the English consonant sounds are very difficult to reproduce for the Russian native speakers (like the initial sounds in think, this), and there is no difference between "w" and "v" for the Russian ear.

The sounds are only the start of the difficulties. The English grammar differs from the Russian grammar by the complex system of tenses. In Russian, there are only three tenses - past, present, and future. All the other details in the shades of the activity are expressed by the prefixes and suffixes. Furthermore, Russian sentences do not have a strict word order and tend to be very long particularly in scientific literature where the subject appears only at the end of the sentence. Another difficulty is the use of definite and indefinite articles. The Slavic languages have no articles at all, and it is always a challenge, even for an experienced Russian-English translator, to insert the correct article which, in some, cases, may change the meaning of the sentence.

Due to all these differences and difficulties, native Russian speakers can produce sentences which sound very awkward in English, but are easily explainable taking into 
consideration the native language structure. At the same time, the sentences are understandable, and their authors feel confident enough to communicate.

While these skills will suffice for day-to-day verbal communication and general understanding, they are insufficient for the purposes of professional communication, both in oral and in written forms [1]. In other words, excellence needs excellence, while being good but not enough means that you are not a competitive engineer.

This paper is dedicated to the challenges of the modern engineering communities speaking Slavic languages (like Russian, Ukrainian and Czech) in their efforts to follow high standards of modern English in education and science. The desired outcome is not an engineer with superb literature-level English skills: that is almost impossible. A reasonable expectation is a professional who will be understood by his or her native English speaking colleagues. A slight mistake can be dangerous in production conditions. Engineering graduates should therefore have polished skills of pronunciation and terminology as well as composition of instructions and safety regulations for their colleagues and subordinates.

A general outcome of scientific activities in universities is the submission of papers to high-impact international journals. Publications in top scientific journals (all of them are published in English) are the main indications of a successful scientist. Native Russian speaking scientists often have trouble writing in English for journals and conferences because of structural differences between the English and Russian languages as described previously. Furthermore many Russians with "unpolished" English" have a strange confidence that the scientific value of their submission will outweigh its linguistic incompetence and a native speaker in editorial board will ultimately "polish" it. The goal of this research is to improve the English teaching curriculum to Russian engineering faculty and to specifically address these problems [2].

A precursor to this activity was a workshop at the 2013 International Scientific School on Engineering Education for New Industrialization held in Kazan, Russia given to native Russian speaking faculty by the author [3]. This workshop focused only on writing titles and abstracts in English. During this workshop it was noticed that several types of errors were often repeated and this repetition caused the authors to delve deeper and research the sources of these errors and understand what kind of exercises could be created to mitigate these errors. This paper provides statistical evaluation of these types of mistakes in the proceedings of the large-scale international conference running in parallel to the workshop with a large portion of Russian speaking submitters. The conference was dedicated to the engineering education and the participants were represented by the engineers and engineering scientists from top Russian universities, regional, national and global companies with Russian stakeholders as well as administrators of Russian ministries and governing bodies involved in engineering education and industry. Such a versatile participation provided a unique opportunity for the analysis of the contributions of non-native English speakers in the Russian engineering community.

The body of submissions was thoroughly analyzed to generate statistics on the types and frequency of errors, various awkward sentences and other poor English components in such submissions. Proposed changes that have come from this research include several aspects. 
The first aspect is that the Russian engineers should consider their papers as turnkey products, which will not need to be polished by editors and that will simply be rejected if English is improper. An introductory mind-changing lecture is offered with the consideration of "turnkey polishing" in the final course score.

Another "mind-changing" paradigm is that an original paper written in English is MUCH better than the translation of scientific results originally prepared in Russian. The brilliance of Russian scientific style becomes a disadvantage in its English translation due to fundamental linguistic and stylistic differences. The engineers should be initially trained to make original publications in English and not stick to the translation of their Russian records.

The practical component of curriculum is based on the approach of a "proper alternative" with bilingual exercises provided with the improper English phrase or term and several variants of proper corrections. More advanced exercises assume that students need to make a proper correction themselves.

The number of specific written exercises is categorized into the following basic groups:

- sentence structure and formation (e.g., "At the present time the middle age of workers in TANECO makes 35 years" instead of "At present, the average age of TANECO employees is 35."), in some cases together with typos (e.g., "The TANECO stuff accounts for 2,3 ths. people" instead of "TANECO employs 2.3 thousand people.");

- set phrases (e.g. "Russia joining the WTO" or "Russian Federation entrance to WTO" instead of "Russia's accession to WTO"; "the conception of life-learning education" instead of "life-long learning"; "thrifty economy" instead of "lean economy");

- sentence punctuation (e.g., "In October, 2009 the University received a high federal status" instead of "In October 2009, the University received a high federal status.");

- the use of capitalized letters (e.g., "Kazan national research technological university" instead of "Kazan National Research Technological University");

- titles of research papers (Using only a general subject area without giving a clear picture of the new contribution that this paper provides is not a good approach. For example, "Shoe Design in Russia" might be ok if an overview and historical review of the Shoe Design was being given but in a general conference session an overview would not be likely. However if the research was on new uses of polymers in shoe construction, then the title was too broad and would not let the audience know what to expect. Instead perhaps the title might be "Innovative New Polymers Transforming Russian Shoe Design") [3];

- the use of "a, an, and the" (Use the former, "a" if the noun or concept is being presented for the first time and subsequent uses of that noun would be preceded by "the");

- international names of Russian companies and organizations based on their official websites and trademarks (e.g., "Trade and Industrial Chamber of the Russian Federation" instead of "Chamber of Commerce and Industry of the Russian Federation", see http://old.tpprf.ru/en/);

- names of scientists in Latin alphabet and common abbreviations (e.g., "WTA" instead of "WTO" for "World Trade Organization"; "Albert Eynshteyn" instead of "Albert Einstein"); 
- proper use of internet resources for the English translations of official events such as conferences (e.g., "42 International Symposium on Engineering Education "Global challenge in the Engineering Education" instead of "42nd IGIP International Conference on Engineering Pedagogy "Global Challenges in Engineering Education");

- formatting errors which can be easily eliminated (e.g., authors often make double or triple spaces when typing their texts in text editors. Simple tools, like $\mathrm{Ctrl}+\mathrm{H}$ are very useful to get rid of such errors);

- the use of dictionaries and databases to overcome terminological issues (e.g., the Russian higher education elements do not have a direct match in the American system, e.g., the US single research degree $(\mathrm{PhD})$ has two equivalents in the Russian system: Candidate of Sciences (first level) and Doctor of Sciences (second level).Proper care must be taken to match these poorly compatible terms in accordance with the context) [4].

The outcome of the research was the development of a highly focused curriculum to rectify these problems.

Kazan National Research Technological University takes a number of efforts to teach its faculty to use the English language properly. In 2013, it's been 3 years that an experiment in teaching English to faculty is going. The English language program for an academic year includes 200 contact hours (an academic hour in Russia is 40-45 minutes) and 100 self-study hours. The experiment started in the 2011-12 academic year when 59 faculty were enrolled, this number grew to around 130 in 2012-2013, and remained at the same level in 2013-2014.

There is a group of 30 people who continue their studies during all the three years. The first two years were given to learn the basics. The result was oral communication skills in visiting other countries and setting partnerships with foreign professors. In the third year, we address the issues of writing papers in English. For this audience, a set of lessons is developed devoted to the structure of an abstract, the sequence of presenting the material (with the right phrases introduced), comparison between the Russian and American university education systems.

Now we can give only a preliminary evaluation of this new curriculum efficiency by analyzing the body of submissions in foreign languages made by the participants. In the previous years, none of them ever participated in real international conferences with peerreviewed papers. Neither could they submit their papers in English to international peerreviewed journals. This year, 11 of the 30 faculty attending the language program have submitted their papers to the international conference on Interactive Collaborative Learning ICL 2014, however, the results of acceptance / non-acceptance will be received by the end of May, 2014. Meanwhile, they are now participating in the peer-review process themselves as reviewers, as this is one of the requirements for participation in the conference, and this is going to be a good experience for all of them.

In the long run, we expect a growing number of submissions to international conferences, which is one of the evaluation factors for a research university. This approach can be further used for developing the language proficiency in engineering education in other Slavic languages. 
[1] Sanger, P.A., Ziyatdinova, J., Barabanova, S.V., Ivanov, V. Challenges of creating a new engineering education model in Russia // (2012) ASEE Annual Conference and Exposition, Conference Proceedings

[2] Sanger, P.A.; Ziyatdinova, J.N. Bridging the communication gap of a foreign speaking instructor in Hands On Pedagogy // Interactive Collaborative Learning (ICL), 2013 International Conference on //Digital Object Identifier: 10.1109/ICL.2013.6644617 // Publication Year: 2013 , Page(s): $433 \quad-435$

[3] Sanger,Ph.A., Ziyatdinova, J.N. Writing in English for international conferences. // Higher Education in Russia, Issue 12-2013, P. 95-99

[4] Bezrukov, A. Flexible Learning Model for Computer-Aided Technical Translation. // Interactive Collaborative Learning (ICL), 2013 International Conference on // Digital Object Identifier: 10.1109/ICL.2013.6644680 // Publication Year: 2013 , Page(s): 673 $-675$ 